\title{
Çağımızın dev sorunu: çocukluk çağı obezitesi
}

\author{
Giant problem of our era: childhood obesity
}

\author{
Ayşegül ALPCAN ${ }^{1 a}$, Şenay ARIKAN DURMAZ²
}

1 Kırıkkale Yüksek İhtisas Hastanesi, Çocuk Sağlığı ve Hastalıkları Bölümü, Kırıkkale, ${ }^{2}$ Kırıkkale Üniversitesi Tıp Fakültesi, Endokrinoloji Bilim Dalı, Kırıkkale -TÜRKIYE

\section{ÖZET}

Vücutta artmış yağ miktarı olarak tanımlanan obezitenin sıklı̆ı ırk, yaş, cinsiyete göre değişiklik gösterir. Çocuk ve adölesanlarda obezite prevalansı dünya çapında artış göstermektedir. Bu artışın en önemli sebebi ise, gelişen teknoloji ile birlikte çocukların hareketliliklerin kısıtlanması, beslenme alışkanlıklarııın ve besin tercihlerinin değişmesidir. Obezite etyolojisinde kalori alımı ve kullanımı arasındaki denge bozukluğu olsa da monogenik obezitede olduğu gibi genetik faktörler, endokrin yıkıcılar olarak bilinen yüzlerce çevresel faktör, barsak microbiatasındaki değişiklikler ve hormonal faktörler de suçlanmaktadır Çocuklarda obezitenin tanısında basit, uygulanabilir, ucuz ve güvenli bir yöntem olan vücut kitle indeksi (VKI) kullanılmaktadır. Erken dönemde ortaya çıkan obezite tip 2 diabetes mellitus, non alkolik hepatosteatoz, hipertansiyon, hiperlipidemi ve kardiyovasküler hastalıklar gibi ciddi komplikasyonlara neden olmaktadır. Çocuklarda obezite tedavisinin temel basamağı yaşam tarzının düzenlenmesi olmasına rağmen ciddi obezite komplikasyonları varsa farmakoterapi veya cerrahi tedavi de önerilebilir

Anahtar Kelimeler: Çocukluk çağı, obezite, risk faktörleri, prevalans, tedavi

\section{ABSTRACT}

The prevalence of obesity, defined as increased amount of body fat, varies according to race, age, and sex. Obesity prevalence in children and adolescents increases worldwide. The most important reason for the increase is, along with developing technology, limitation of activity, and alterations in nutritional habits and food preferences of the children. Although there is imbalance of calorie intake and utilization in the etiology of obesity, genetic factors as in monogenic obesity, hundreds of environmental factors known as endocrine destructors, changes in intestinal microbiota, and hormonal factors are also accused. Body mass index (BMI), a simple, practical, cheap, and safe method, is used in the diagnosis of obesity in children. Obesity occurring in early period causes serious complications such as, type 2 diabetes mellitus, non-alcoholic hepatosteatosis, hypertension, hyperlipidemia, and cardiovascular diseases. Although the basic step in the treatment pf obesity in children is life-style regulations, pharmacotherapy or surgical treatment are also recommended, if there are serious obesity complications.

Key Words: Childhood, obesity, risk factors, prevalence, treatment 


\section{Giriș}

Vücutta artmış yağ miktarı olarak tanımlanabilen obezite yalnızca yetişkinlerde değil çocukluk çağında bile ortaya çıkan metabolik bir hastalıktır. Obezite oluşumunda temel sorun kalori alımı ve kalori kullanımı arasındaki dengenin bozulması olsa da monogenik obezitede olduğu gibi genetik faktörler, endokrin yıkııılar olarak bilinen yüzlerce çevresel faktör, barsak mikrobiatasındaki değişiklikler ve hormonal faktörler suçlanmaktadır $[1,2,3]$. Obezite beraberinde getirdiği sorunlar nedeniyle tek bir hastalık olarak kabul edilmemelidir [4]. Çocukluk çağında başlayan obezite ve yarattığı insulin direnci tip 2 diyabetin çok erken yaşlarda görülmesine, çocuk ve adölesanlarda hipertansiyona, eşlik eden hiperlipidemi ile beraber metabolik sendroma yol açarak yetişkin çağda kardiyovaskuler olaylara zemin hazırlamaktadır [5].

Dünya sağlık örgütünün 2010 verilerine göre 43 milyon okul öncesi çocuk fazla kilolu veya obezdir ve 1990 yılı ile kıyaslandığında ise \%4,2'lik artış görülmektedir [6].

Gelişen teknoloji ile birlikte çocuk ve ergenlerde fiziksel aktivite oldukça azalmışıı. Artık çocuklar boş zamanlarını park bahçede oynayarak geçirmek yerinde televizyon veya bilgisayar başında geçirmeyi tercih etmektedir. Günümüzde yanlış beslenme alışkanlıklarının kazanılması ile (fast food tarzı beslenme, hazır gıda tüketiminde artış, vitamin ve posa yönünden zayıf beslenme, televizyon karşıında beslenme) kalori alım dengesi de bozulmuştur $[7,8]$.

Obezite fenotipik olarak hemen dikkat çekse de vücuttaki yağ miktarını objektif olarak ölçen birçok tanısal yöntem bulunmaktadır. Çocuklarda obezitenin tanısında genelde basit, uygulanabilir, ucuz ve daha güvenli olan vücut kitle indeksi (VKI) kullanılmaktadır. Vücut kitle indeksi çocuğun vücut ağırlı̆ıının (kg), boy uzunluğunun (metre) karesine bölünmesi ile hesaplanır [9]. Çocuklarda yetişkinlerden farklı olarak VKI yaşa ve cinsiyete göre değişiklik göstermesi nedeniyle VKI persantilleri vardır. Bu eğrilere göre 85 persantil üzerinde olanlar fazla kilolu, 95 persantil üstünde kalanlar ise obez olarak sınıflandırımaktadır $[10,11]$. Diğer bir kolay yöntem ise boya göre ağırlık ölçümüdür. Boya göre ağırlı̆ın \%120 üstünde olması obezite olarak tanımlanır. [12,13]. Daha sofistike yöntemler olan; su tartımı ile vücut dansitometrisi, total vücut suyu hesaplanması, toplam vücut potasyum ölçümü, nötron aktivasyon analizi, ultrasonografi (USG), bilgisayarlı tomografi, manyetik rezonans görüntüleme yöntemi, biyoelektriksel impedans (Bioelectric Impedans Analysis, BIA), total vücut geçirgenliği (Total Body Electrical Conductivity, TOBEC), dual foton absorpsiyometre (DPA) ve dual enerji X-ışını absorpsiyometre (DEXA) gibi direk vücut yağ oranını hesaplamak için uygulanabilir [11-15]. Fakat bu yöntemlerin çocuklarda hem uygulaması çok zordur hem de oldukça pahalı tetkiklerdir $[10,11,16]$.
Başka ölçüm bir yöntemi de kaliper denilen özel araç ile deri kıvrım kalınIı̆ı ölçümüdür. Vücut toplam yağ oranının yarısının deri altında toplandığı gerekçesine dayalı bir yöntemdir. Çocuklarda en uygun ölçüm yeri triseps cilt kalınlığılır. Yine çocuklar için yaşa ve cinsiyete göre persantil çizelgelerinde \%85 üstü fazla kilolu, \%95 üstü ise obez kabul edilmektedir. Dezavantajı çocukların deri kıvrımı ölçümü yaptırmak istememesi olabilir $[17,18]$.

Vücut kitle indeksi, fazla kilolu ve obez çocuklar için kullanılan tanısal yöntem olsa da vücut yağ oranı hakkında bize kesin bilgiyi sağlamaz [19]. Bu sebeple bel çevresi, bel çevresi / boy oranı ve boyun çevresi ölçümü yapılabilir [20]. Boyun çevresi ölçümü çocuk ve adölesanlardaki vücut yağ oranını ölçmede oldukça iyi bir yöntemdir [21]. Fakat kaynaklarda bu üç yöntemle ilgili çocuklar için belirlenmiş parametreler yoktur [22]. Yine bir çok kaynakta bel çevresi/boy oranı çocuk için önemlidir Bu oranın 0,5'in üstüne çıkması yağ oranının artışılya ilişkilidir [23-25]. Bel çevresi ölçümü ile vücut kitle indeksi, vücut yağ oranı arasında orantılı bir iliş̧i vardır. Bir çok çalışmaya göre bel çevresi bize abdominal obezite hakkında uygun bilgiyi sağlar. Bel çevresinin 90 persantil üzerinde olması kritik değer olarak kabul edilmektedir [26-28].

\section{Obezite Sıklı̆ı̆}

Obezite sıklı̆ıı ırk, yaş, cinsiyete göre değişiklik gösterir. Amerika Birleşik Devleri'nde çocuk ve adölesanlarda prevalansı oldukça artış göstermekte olup, fazla kilolu adölesan çocuk sıklığı \%21-24 arası değişirken, obez çocuk ve adölesanlarda sıklığı \%16-18 arası değişmektedir [29]. Amerika Birleşik Devletleri'nde 1988 ile 1994 yılları arasında yapılan beslenme ve sağllk taramasında 6 ile 11 yaş arsındaki çocukların \%13,7'sinde, 12 ile 17 yaş arsı çocukların ise \%11,5'inde vücut kitle indeksi 95 . persentil üzerinde tespit edilmiş̧ir [30]. Amerika'da 2003 ile 2006 yılları arasında yapılan beslenme ve sağlık taramasında ise çocuk ve adölesanların \%16,3'ü obez tespit edilmiştir [31]. Avrupa'da ise fazla kilolu erkeklerin prevalansı erkeklerde $\% 17$ ve kızların ise $\% 14$ bulunmuştur [32]. Çin'de adolesan ve çocuklarda obezite oranı yaklaşık \% 12 bulunmuştur [33].

Türkiye'de 2001 ile 2002 yılları arasında yapılan çalışmaya göre 11 yaş grubundaki kızların \%7'si, erkeklerin \%14'ü, 13 yaş grubundaki çocuklardan kızların \%7'si, erkeklerin \%13'ü, 15 yaş grubundaki çocuklardan kızların \%5'i, erkeklerin ise \%14'ü obezdir [34]. Dünya sağllk örgütü 2009 yllı verilerine göre Türkiye' de çocuklarda obezite prevelansı $\% 16,1$ 'dir. Cinsiyetlere göre bakıldığında prevelans, erkeklerde $\% 15,6$, kılarda \%23,9 olarak tespit edilmiştir [35]. il bazında Türkiye'deki çocukluk çağı obezitesi yüzdeleri Tablo-1 de görülmektedir il bazındaki farklılıkların bölgesel beslenme alışkanlığına, yapılan çalışmanın yapıldığı yer, çalışmanın yapııdığı yerin kültür düzeyine bağlı olarak değiştiği düşünülmektedir [36]. 
Tablo 1: Türkiye'de yapılan çalışmalara göre obez çocukların il bazında sıklı̆ı (\% olarak) (36-44)

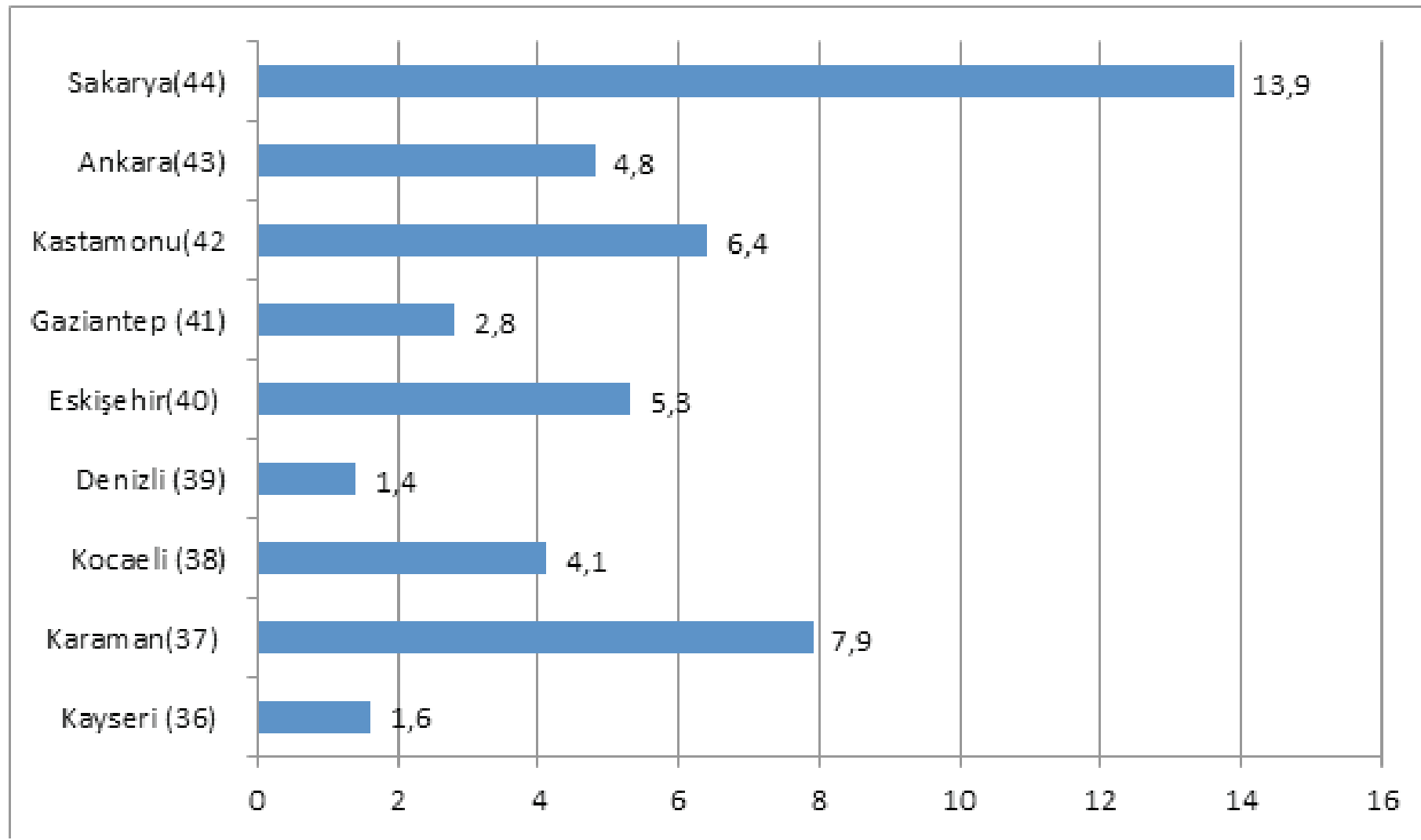

\section{Obezite Nedenleri}

Obezitenin oluşumuna sebep olan birçok faktör bulunmaktadır.

\section{Genetik Faktörler}

Ailede obez birey olması çocuk için risk faktörü oluşturmaktadır. Her iki ebeveyn de obez ise çocukta obezite riski \%80'lere kadar çıkabilmektedir. Fakat aile ilişkisinin, hem genetik aktarış ile olması hem de beslenme alışkanlığının ailede kazanılması açısından önemli olduğu unutulmamaIIdır $[45,46]$.

Obeziteye neden olan genler bireyde direkt olarak kilo alımına sebep olmazlar. Ancak kilo alımına neden olacak ortamlara maruz kaldıklarında diğer insanlara göre kilo alma riski belirgin olarak artmaktadır (16).

Obeziteye neden olabilecek tek gen defektleri tespit edilmiştir. Zang ve ark. [47] tarafindan 1994 ylında keşfedilen adipoz dokudan salınan ve ob geni üzerinden kodlanan leptin miktarı, vücutta bulunan yağ dokusu miktarına göre ayarlanmaktadır. Leptinin etkisi hipotalamus üzerine olup yağ ve karbonhidrat metabolizmasından sorumludur. Leptinin beyaz yağ dokusu dışında mide, epitelyum hücreleri, plasentadan da salındığı bilinmektedir $[48,49]$ Leptin asll etkisi hipotalamus üzerinde etkili olarak iştahı baskılamaktadır. Yani açııta leptin düzeyi azalırken, fazla beslenme sonucunda leptin düzeyinde artış olmaktadır [50,51]. Leptin reseptörlerinde direnç olduğunda veya leptin üretiminde azalma olduğunda leptin bağımlı obeziteden bahsedilmektedir [49,52,53].

Ayrıca genellikle konjenital malformasyonların veya nörolojik hastallkların eşlik ettiği 140 farklı sendromik obezite tanımlanmıştır (54). Alström Sendromu, Prader-Willi Sendromu, Laurence-Moon-Biedl (Bardet-Biedl
Sendromu), Cohen Sendromu, Down Sendromu, Turner Sendromu obezite ile ilişkilidir [2].

Alström sendromu; otozomal resesif geçişli multisistemik bir hastalıktır. Hastalarda retinal distrofiye bağlı gelişen körlük, işitme kaybı, infantil veya adölesan dönemde başlayan kardiyomyopati, hiperinsülinemi, hiperlipidemi, tip 2 diabetes mellitus, obezite, pulmoner ve hepatik ve renal yetmezlik görülebilir $[54,55]$.

Illk olarak 1956 yllında tanımlanan Prader Willi sendromu ise kompleks genetik bir hastalıkdır [56]. Neonatal hipotoni, karakteristik yüz görünümü, kısa boy, çocukluk çağı obezitesi, hipogonadizm, gecikmiş puberte en önemli bulgularıdır. Hastalarda orta-hafif düzeyde mental retardasyon görülebilir. Morbid obezitenin en önemli nedenlerinden biridir $[56,57]$. Prevalansı yaklaşık 250000 doğumda birdir. Literatürde bildirilmiş yaklaşı 400000 olgu bulunmaktadır. Hastaların hipotalamus-hipofiz aksında bozukluk vardır. Hastalarda 15. otozomal kromozomun uzun kolunda 11 ile 13 segmentler arası bölgedeki delesyondur (15q11-13) [58-60].

Hastalarda erken dönemde kilo fazlalığı olmasa dahi vücut yağ oranı artmıştr. Erken dönemde başlayan obezite, komplikasyonların daha erken dönemde ortaya çıkması ve daha ciddi seyir göstermesi nedeniyle önemlidir [61,62].

Laurence Moon Bardet Biedl Sendromu (LMBBS); Hipogonadizm, obezite, polidaktili, retinitis pigmentoza, zeka geriliği ile karakterizedir Erken çocuklukta başlayan obezite ve özellikle de trunkal obezite en sık görülen bulgulardandır. Obezite genelde 4 yaş civarında başlar ve gövdede yaygındır. Hastalarda belirgin boy kısalı̆ıı dikkati çeker [63-65]. 


\section{Hormonal ve metabolik nedenler}

Hipotirodi, puberte prekoks, polikistik over sendromu, prolaktin sekrete eden tümörler, büyüme hormonu eksikliği ve direnci gibi sebeplerin de sekonder obeziteye yol açı̆ı̆ı unutulmamalıdır [66-70].

\section{- Hipotalamik obezite}

Hipotalamusun hasarı, tümörü, travması, radyoterapi sonucu oluşabilir. Direkt olarak iştah ve doyma merkezi etkilenir ve genelde morbid obezite ile sonuçlanır [66,67].

\section{- Hipotiroidi}

Infant ve çocukluk döneminde hipotiroidide, büyüme geriliği, mental retardasyon ve seksüel gelişimin geri kalması en belirgin bulgudur Obeziteye etkisi erken dönemde ortaya çıkmaz. Erişkin dönemde kilo alımı ortaya çıkar. Hastalarda yaygın ödeme bağlı olarak kilo alımı söz konusudur [70,71].

\section{- Büyüme hormonu eksikliği}

Büyüme hormonunun yağ yıkımını artırıcı, enerji tüketimini tetikleyici etkisi vardır. Büyüme hormonu eksikliğinde vücut yağ miktarında artma oranı artışı ve artmış plazma leptin seviyeleri ile birliktedir $[49,72]$.

\section{- Polikistik over sendromu}

Poliksitik over sendromu pubertede başlar. Hastalarda hiperandrojenizme bağlı düzensiz menstruasyon, kıllanma, akne, erkek tip sac dökülmesi olmaktadır. Bu hastalarda meydana gelen hiperinsulinizm vücut ağırığının ve yağ birikiminin artmasına neden olmaktadır $[66,72]$.

\section{- Intestinal mikrobiyota ve obezite}

Intestinal ekosistem trilyonlarca (yaklaşık 1014) bakteri, virüs, mantar gibi mikroorganizmadan oluşmuştur. Normal şartlarda bu mikroorganizmalar denge içindedirler. Günlük beslenme ve çevresel etkilerle değişim gösterirler. Beslenme bu dengeyi etkileyen en önemli faktördür. Birçok çalışmada obezite ve komplikasyonlarının bu intestinal mikrobiyota değişimiyle ilişkili olduğu gösterilmiştir $[74,75]$. İntestinal sistemin mikrobiyatasındaki bakteriler Firmicutes, Bacteroidetes, Proteobacteria, Actinobacteria, Fusobacteria ve Verrucomicrobia olarak sayllabilir. Bacteroidetes ve Firmicutes yaklaşık \%90'ını oluşturur [76-78]. İntestinal sistemdeki mikrobiyotaların birçok faydası vardır. Barsak mukoza bütünlüğünün korunması, besin absorbsiyonu, enerji dengesinden sorumludurlar [79]. Birçok insan ve hayvan deneyi intestinal mikrobiyata ve obezite veya kilo değişiklikleri ilişkili olduğunu göstermiştir [75]. İnsan obezitesinin bacteroidetes miktarında azalma, Firmicutes miktarında artış yani bakteri oranlarındaki değişiklik ile olduğu gösterilmiştir [80-82]. Obez çocuklar ile zayıf çocukların barsak mikrobiyataları karşılaştııılı̆̆ında farklı olduğu gösterilmiştir (83-85). Bifidobacterium normalde konakçıda önemli roller oynamaz. Fakat yüksek yağlı diyet ile miktarı azalmakta buna bağlı olarak sekonder inflamatuar yanıt ortaya çıkar, vücut yağ miktarı artar, insülin direnci gelişir. Fakat kilo verme veya düşük kalorili beslenme ile bu olaylar gerilemektedir $[84,87]$. Yüksek enerjili beslenme ile barsak mikrobiyota içeriği değişmektedir. Bunun sonucunda da çeşitli inflamatuar olaylar tetiklenmekte ve vücut yağ deposu artmaktadır [88]. Obez fare ve insanlardaki mikrobiyotaların karbonhidrat fermantasyonunu artırdığı gösterilmiştir. Bunun sonucunda da serbest yağ asitleri olan asetat, propionat, bütirat, L-laktat artar. Ortaya çıkan serbest yağ asitleri intestinal ph azalmasında ve enerji metabolizmasında, immünitede, yağ doku miktarında, kanser hücre yapılanmasında etkilidir $[76,89)$. Bu dengenin bozulması ile birlikte lipoliz inhibe olur ve yağ doku miktarı artar. Monosakkaritlerin mikrobiyal fermentasyonu artar, portal vene geçer, hepatik lipogenezi tetikler ve karaciğer yağlanması ortaya çıkar [90,91]. Mikrobiyotaların miktarındaki \%20'lik bir değişim 150 kcal ektra kalori sağlar [92]. Mikrobiyotadaki değişikliklerin, alınan bu fazla kalori ve serbest yağ asitlerinin etkisi ile obezite oluşuma katkı sağladığı düşünülmektedir $[75,76]$.

\section{Azalmış fiziksel aktivite}

Televizyon izlemek gelişmiş ülkelerdeki çocukluk çağı obezitesine neden olan çevresel etkenlerin başında gelmektedir. Amerika'da yapılan bir çaIsşmaya göre 8 ile 18 yaş arasındaki çocuklar günde 7,5 saatini, 6 yaşın altındaki çocuklar ise günde 2 saatini medya karşında geçirmektedir [93]. Fiziksel aktivitenin azı̆ı̆ı obeziteye neden olsa da obezitenin bir etkisi olarak da fiziksel aktivite kısıllanmaktadır. Bu bir döngü halinde gelmektedir $[94,95]$.

\section{4. Çevresel faktörler ve aile}

Çocuklardaki obezitenin oluşumu prenatal dönemden kaynaklanabilir. Annenin obez olması veya gebelikte fazla kilo alması çocukta bir risk faktörü olarak tanımlanabilir. Annenin gebelik döneminde beslenme bozukluğu çok önemlidir. Erken dönemde ciddi derecede malnütrisyonda olan annenin bebeklerinin ileri dönemlerde obez olduğu gösterilmiştir. Tam tersi gebelikte annenin fazla beslenmesi, annenin hiperglisemik olması sonucunda bebekte de glukoz intoleransı gelişimine neden olmaktadır [96,97].

\section{5. İlaçlar}

Obezite nedenleri içinde sayılan ilaç yan etkilerinden bir olan obezite genelde fark edilmez. Glukokortikoidler, trisiklik antidepresanlar, antitiroid ilaçlar, östrojen, progesteron, lityum, fenotiyazin, siproheptadin kullanımları obeziteye neden olabilen ilaçlardır [66].

\section{Obezitenin Komplikasyonları}

Erken dönem obezite metabolik bozukluklara yol açmaktadır. En sık görülen komplikasyonu tip 2 diabetes mellitus, nonalkolik hepatosteatoz, hipertansiyon, hiperlipidemi ve kardiyovasküler hastalıktır [98].

\section{Karaciğer yağlanması}

Obez çocuklarda ve adölesanlarda karaciğer hastalığının en sık sebebi karaciğer yağlanmasıdır [99]. Çocukluk çağındaki obezite sıklığın artışı ile alkole bağlı olmayan karaciğer yağlanması sıklığı da artmıştır. Alkole bağlı olmayan karaciğer yağlanması biyopsi ile hepatositlerin \%5'inden fazlasında yağ infiltrasyonun görülmesi ile konulur. Hastada ek bir viral hastalık, alkol alımı, ilaç alımı olmamalıdır. Amerika'da normal kilolu çocuklarda biyopsi ile ispatlanmış prevalansı \% 9,6 iken, obez çocuklarda bu sayı \%38'dir [100,101]. Tanıda ultrasonografi güvenilir, ucuz, kolay olması sebebiyle tercih edilir. Fakat sensitivitesi hepatik yağ birikimi 
\%30'un altında ise düşüktür. Tedaviye yanıt alınamıyorsa biyopsi önerilir (102). Tedavide fiziksel aktivitenin artırıması, uygun beslenme ve kilo verme önerilir. İnsülin direnci varsa metformin başlanabilir. Tedavide ursedokolik asit verilebilir [103].

\section{Obeziteyi Önleme ve Tedavi}

Çocukluk çağı ve adölesanda obezite tedavisindeki temel amaç kilo vermekten ziyade beslenme ve egzersiz alışkanlığı kazandırmak olmalıdır. Hastalara kilo verdirirken amaç 2 ile 5 yaş arası çocuklarda ayda yaklaşık 500 gramı, 6 ile 18 yaş arası çocuklarda ise haftada yaklaşık 1000 gramı geçmemelidir [104]. Çalısmalarda diyet, egzersiz ve davranış değişikliği ile çocukluk çağı obezitesi tedavisinde ve obezitenin kardiyo-metabolik etkileri üzerinde en geç bir yılda yanıt almak mümkündür. Çocuk ve aile obezite ve obezitenin komplikasyonları hakkında bilinçlendirilmelidir [105,108].

\section{- Beslenme Tedavisi}

Ailenin koruma ve tedavide çok önemli olduğu, beslenme alışkanlığının ailede kazanıldığı, aile bireylerinin olumlu örnek olmaları anlatılmalıdır [109]. Hastalar ögün atlamamalıdır, televizyon karşında beslenme önlenmelidir. Çocukların aile ile birlikte aynı sofrada beslenmesi sağlanmalıdır [110]. Arada alınan atışıımalar ve abur cubur tüketimi önlenmeli sebze ve meyve içeren posalı ve kuru baklagilleri içeren yiyeceklerin tüketimi sağlanmalıdır [111]. Hastaların düşük enerjili, çabuk kilo verdiren moda diyetlere yönelmesi engellenmelidir. Ödül olarak yüksek kalorili yiyeceklerin tüketilmesi önlenmelidir [109,111].

Sondrike ve ark. [112] randomize kontrollü bir çalışmada düşük karbonhidrat ve yüksek protein diyeti ile düşük yağ alımın olduğu diyeti fazla kiIolu adölesanlarda karşılaştırmışlardır. Düşük karbonhidrat grubu 2 hafta boyunca günlük 200 gramın altında karbonhidrat almış, daha sonraki 10 hafta ise günlük 40 gramın altında karbonhidrat verilmiş̧ir. Düşük yağ grubunun ise günlük kalori alımındaki yağ oranı \%30'u geçmeyecek şekilde sınırlandırımıştır. Düşük karbonhidrat grubu 3 ayda 9,9 kg verirken düşük yağ grubu 3 ayda 4,9 kg zayıflamışır. Yağ miktarının düşük miktarda alan grupta LDL düzeyi düşüşü görülürken düşük miktarda karbonhidrat tüketen grupta bu düşüş görülmemiştir. Düşük miktarda karbonhidrat tüketen grupta yan etki görülmemiştir [112].

Genel olarak çocuk ve adölesanlarda beslenme ayarlanırken boy kilo gelişimin yaşına göre geride kalmaması da sağlanmalıdır. Kalori gereksinimi \%30-40 kadar azaltılır. Hastanın haftalık 0,5 kg vermesi amaçlanır. Yağ ve şeker oranı kısıtlanmalı, günlük kalorinin \%25-30'unu yağ, \%50-55'i karbonhidrat ve \%20-25'ini protein içermelidir [109-111].

Tedavi sonucunda hastaların \%5-10 kadar ağırlık kaybı obezite komplikasyonlarının önlenmesi için önemlidir [113,114].

\section{- Egzersiz}

Obezite tedavisinde diğer bir basamağı fazla kalorilerin tüketimi oluşturur. Egzersizin, enerji tüketimini artıııı, bazal metabolizma hızını artıııı, iştahı azaltıc etkileri vardır. Egzersiz ile yağ dokusu kaybı olmaktadır. Bunun sonucunda geri kilo alımının önlenmesi sağlanır. Çocuğun televizyon izleme, bilgisayar oynama gibi alıskanlıklarını kısıtlandırılıp aktif egzersiz yapması sağlanmalıdır. Bu egzersizler bisiklete binme, koşma, okul takımlarında yer alma gibi orta dereceli olabilir [115]. Ancak günde 20-30 dakika düzenli yürüme bile kilo kontrolünü sağlayabilir $[116,117]$.

Dünya sağ Ik örgütü 5 ile 17 yaş arasındaki çocuklara günde en az 60 dakika orta ağır egzersiz önermektedir. Fiziksel aktivite 60 dakikadan uzun tutulursa yararlı etkilerinden faydalanılabilir. Fiziksel olarak inaktif çocuk ve gençlerde aktivitelerin yavaş yavaş artıııması sağlanmalıır [117].

Ayrica egzersiz kan basıncı, serum kolesterolü, psikolojik durum, kardiyovasküler sistem üzerine de faydaları vardır. Yani egzersiz hem kilo verilmesinde, hem verilen kilonun geri alımını önlenmesinde, hem de obezite nedeniyle ortaya çıkabilecek sorunların önlenmesinde etkilidir [113-117].

\section{- İlaç Tedavisi}

Çocuklarda obezite tedavisinin temel basamağı yaşam tarzının düzenlenmesi olmasına rağmen insülin rezistansı, hipertansiyon, dislipidemi, obstruktif uyku apnesi gibi ciddi obezite komplikasyonları varsa farmakoterapi önerilebilir [118,119].

Orlistat: Şu anda FDA tarafından 12 ile 16 yaş arasında kilo verdirici olarak kullanılmasına onay verilen tek ilaçdır. Vücut kitle indeksinde $\% 0,5$ ile 4,2 kg/m² azalma sağladığı gösterilmiştir [120-123]. Trigliseridlerin intestinal absorbsiyonunu \%30'a kadar azaltmaktadır. Bu sebeple de en sık görülen yan etkisi gastrointestinal sistem üzerinedir. Kullanımı erişkindeki gibidir. Günde 3 defa $120 \mathrm{mg}$ şeklinde alııı. Illacın yağda çözünen vitaminlerin atlımına etkisi sebebiyle ilacın alımından 2 saat öncesinde multivitamin kullanımı önerilir [124,125]. Iştah üzerine etkisi yoktur.

Metformin: Insülin direncinin olduğu tip 2 diabetes mellutusda ve polikistik over sendromunda kullanilır. Çocuklarda kullanımı 10 yaşın üstündedir. Ağıllık, vücut kitle indeksi ve bel çevresi üzerine etkisi vardır. Tedavi sonucunda açlık insülin seviyesinde düşme sağlar [126]. Periferik dokuda glukozun kullanımı ve insülinin etkisini artıırı. Karın ağrısı, şişkinlik, bulantı, kramplar, ishal gibi gastrointestinal yan etkisi vardır. Günlük $850 \mathrm{mg}$ kullanımı ile açlık insülin düzeyinde düşmenin yanı sıra lipit seviyesinde de olumlu sonuçlar alınır [127].

\section{- Cerrahi Tedavi}

Genel olarak vücut kitle indeksi $40 \mathrm{~kg} / \mathrm{m}^{2}$ nin üstünde olan obezlerde eşlik eden diabetes mellitus, uyku apnesi, psödotümör serebri varsa, vücut kitle indeksi $50 \mathrm{~kg} / \mathrm{m}^{2}$ ve üzerinde olan obezlerde hipertansiyon, dislipidemi, gastro-özefageal reflü hastalığı varsa ve 6 aylık uğraşım sonunda kilo verilmemişse uygulanmaktadır. Çocuklarda bu konuda çok fazla deneyim yoktur $[128,129]$.

\section{Sonuç}

Obezite teknolojik değişimlerle birlikte sıklğı çocuklarda ve erişkinlerde son zamanlarda artış gösteren, komplikasyonları oldukça ciddi olan, yaşam kalitesini düşüren bir hastalıktır. Eğer önlem alınmazsa sıkıı̆ının daha da çok artacağı düşünülmektedir. Obez çocukların hayatları hem obezitenin komplikasyonları, hem de psikolojik yönden kssitlanmaktadır. Obezitenin önlenmesi veya sıkığın azalması açısından neden olan etmenIerin mutlaka araştırıması gerekir. Tedavi ve korunmada önemli basamağı çocuk için temel eğitim yeri olan ailenin eğitimi oluşturmaktadır. Ailede kazanılan alışkanlıklar ömür boyu sürmektedir. Aileler ve çocuklar düzenli 
ve doğru beslenme hakkında eğitilmeli, alınan kalorilerin harcanması için egzersiz yapılması sağlanmalı ve egzersiz için olanaklar oluşturulmalıdır. Obezite tedavisindeki amacımı da kilo vermeyi hedeflemek kadar doğru yaşam tarzının aile ve çocuğa öğretilip tekrar kilo almayı önlemek ve "geleceğimizi korumak" olmalıdır.

\section{Kaynaklar}

1. Berberoğlu M. Adölesanlarda Obezite. STED 2008;63:79-80.

2. Schwarz S. Obesity in children. http: // emedicine.medscape.com article / 985333-overview. Update dec 4,2013 Erişim tarihi Aralık 2014.

3. Munyaka PM, Khafipour E, Ghia JE. External influence of early childhood establishment of gut microbiota and subsequent health implications. Front Pediatr. 2014;2:1-9

4. Strauss RS. Childhood obesity and self-esteem. Pediatrics. 2000;105:15.

5. Weiss R, Dziura J, Burgert TS, et al Obesity and the metabolic syndrome in children and adolescents. N Engl J Med 2004;350:2362-74.

6. de Onis M, Onyango A, Borghi E, Siyam A, Blössner M, Lutter C; WHO Multicentre Growth Reference Study Group. Worldwide implementation of the WHO Child Growth Standards. Public Health Nutr 2012;15:1603-10.

7. Öztora S. (2005) Illköğretim Çağındaki Çocuklarda Obezite prevalansının Belirlenemsi ve risk faktörlerinin Araştırılması. Bakırköy Tıp Fakültesi Uzmanlık Tezi.

8. Bağrıaçık N, Onat H, İhan B ve ark.. Obesity profile in Turkey. İnternational of Journal Diabetes Metabolism 2009;17:5-8.

9. Cole TJ, Freeman JV, Preece MA. Body mass index reference curves for the UK, 1990;73:25-9.

10. Must A, Dallal GE, Dietz WH. Reference data for obesity: 85th and 95th percentiles of body mass index (wt/ht2) and triceps skinfold thickness. Am J Clin Nutr 1991;53:839-46.

11. Ellis KJ, Shypailo RJ, Pratt JA, Pond WG. Accuracy of dual-energy $x$-ray absorptiometry for body-composition measurements in children. Am J Clin Nutr 1994;60:660-5.

12. Rasmussen MH, Frystkyk J, Andersen T, et al The impact of obesity, fat distribution and energy restriction on Insulin-Like Growth Factor-1 (IGF-1), IGFbinding protein-3, insulin and growth hormone metabolism 1994;43:315-9.

13. Fowler PA, Fuller MF, Glasbey CA, et al Total and subcutaneous adipose tissue in women: The measurement of distribution and accurate prediction of quantitity by using magnetic resonanace imaging. Am J Clin Nutr 1991;54:18-25

14. Goulding A, Taylor RW, Gold E, Lewis-Bernard NJ. Regional bodyfat distribution in relation to pubertal stage : a dual energy $X$-ray absorptiometry study of New Zeland girls and young women. Am J Clin Nutr 1996;64:546-51.

15. Alikaşifoğlu A, Yordam N. Obezitenin tanımı ve prevalansı. Katkı pediatri dergisi 2000;21:475-81

16. Gürel S, İnan G. Çocukluk Çağı Obezitesi Tanı Yöntemleri, prevalansı ve Etyolojisi.ADÜ Tıp Fakültesi Dergisi 2001;2:39-46
17. Lohman TG. Skinfolds and body density and their relation to body fatness: A review.Hum Biol 1981;53:181-225.

18. Sloan AW, Weir JB. Nomograms for prediction of body density and total body fat from skinfold measurements. J Appl Phsiol 1970;28:221-2.

19. Hatipoglu N, Mazicioglu MM, Kurtoglu S, Kendirci M. Neck circumference: an additional tool of screening overweight and obesity in childhood. Eur $\mathrm{J}$ Pediatr 2010;169:733-9.

20. Taylor RW, Jones IE, Williams SM, Goulding A. Body fat percentages measured by dual-energy $\mathrm{X}$-ray absorptiometry corresponding to recently recommended body mass index cutoffs for overweight and obesity in children and adolescents aged 3-18 y. Am J Clin Nutr 2002;76:1416-21.

21. Guo X, Li Y, Sun G, Yang Y, Zheng L, Zhang X et al Prehypertension in children and adolescents: association with body weight and neck circumference. Intern Med 2012;51:23-7.

22. Silva Magalhães El, Rocha Sant'Ana LF, Priore SE, Castro Franceschini SD. Waist circumference, waist/height ratio, and neck circumference as parameters of central obesity assessment in children. Rev Paul Pediatr 2014;32:273-81.

23. Soar C, Vasconcelos Fde A, Assis MA. Waist-hip ratio and waist circumference associated with body mass index in a study with schoolchildren. Cad Saude Publica 2004;20:1609-16.

24. Damasceno MM, Fragoso LV, Lima AK, Lima AC, Viana PC. Correlation between body mass index and waist circumference in children. Acta Paul Enferm 2010;23:652-57.

25. Ricardo GD, Gabriel CG, Corso AC. Anthropometric profile and abdominal adiposity of school children aged between 6 and 10 years in southern Brazil. Rev Bras Cineantropom Desempenho Hum 2012;14:636-46.

26. Mccarthy HD, Cole TJ, Fry T, Jebb SA, Prentice AM. Body fat reference curves for children. Int J Obes (Lond) 2006;30:598-602.

27. Mushtaq MU, Gull S, Abdullah HM, Shahid U, Shad MA, Akram J. Waist circumference, waist-hip ratio and waist-height ratio percentiles and central obesity among Pakistani children aged five to twelve years. BMC Pediatrics 2011;11:105.

28. Brannsether B, Roelants M, Bjerknes R, Júlíusson PB. Waist circumference and waist-to-height ratio in Norwegian children 4-18 years of age: reference values and cut-off levels. Acta Paediatr 2011;100:1576-82.

29. Ogden CL, Yanovski SZ, Carroll MD, Flegal KM. The epidemiology of obesity. Gastroenterology 2007;132:2087-102.

30. Styne DM. Childhood and adolescent obesity, prevalence and significance. Pediatr Clin North Am 2001;48:823-54.

31. Centers for Disease Control and Prevention.National Health and Nutrition Examination Survey 2003-2006. Available at: http://www.cdc.gov/nchs/ nhanes.htm.

32. Freedman DS, Serdula MK, Srinivasan SR, Berenson GS. Relation of circumferences and skinfold thicknesses to lipid and insulin concentrations inchildren and adolescents: the Bogalusa Heart Study. Am J Clin Nutr 1999;69:308-17. 
33. Ji CY, Sun JL, Chen TJ. Dynamic analysis on the prevalence of obesity and overweight school-age children and adolescents in recent 15 years in China (Abstract). Zhonghua Liu Xing Bing Xue 2a Zhi 2004;25:103-8.

34. Inequalities in young People's Health, HBSC International Report from the 2005/2006 survey. WHO Regional Office for Europe, Denmark, 2008 .http://www.euro. who.int/eprise/main/WHO/informationSources/Publications/Catalogue/20080617-1.

35. Word Health Organization (WHO). Global recommendations on physical activity for health. Geneva:WHO; 2010.

36. Krassas GE, Tsametis C, Baleki V, Constantinidis T, Ünlühizarcý K, Kurtoðlu $S$, Keleptimur F, Balkan Group for the study of obesity. Prevalence of overweight and obesity among children and adolescents in Thessaloniki- Greece and Kayseri-Turkey. Pediatr Endoc Rev 2004:1:460-4.

37. Altunkan H. Karaman ilinde 6-19 Yaş Grubu çocuklarda Obezite Prevalansı. Tıp araştırmaları Dergisi 2013;11:6-11.

38. Uçar B, KIlıç Z, Güneş E, ve ark. Eskişehir okul çocuklarında obezite sıklığı ve obezitenin lipid ve lipoprotein profili üzerine olan etkisi.XL. Milli Pediatri Kongresi Özet Kitabl; 1996. p. 42.

39. Semiz S, Özdemir ÖMA, Özdemir AS. Denizli Merkezinde 6-15 Yaş Grubu Çocuklarda Obezite Sıkığı. Pamukkale Tıp Dergisi 2008;1:1-4.

40. Çoşkun Y, Bayraktaroğlu Z. Coranary risk factors in Turkish school children. Acta Pediatr 1997;86:187-91.

41. Uçkun A, Teziç T, Sipahi T. Adolesanlarda obezite: 1620 okul çocuğunun tarama sonuçları. XXXVII. Türk Pediatri Kongresi Özet Kitabı; 2001. p. 212.

42. Tütüncü I, Kastamonu II Merkezinde 13 Illköğretim Okulunda 5-15 Yaş Grubu Öğrencilerde Fazla Kiloluluk ve Obezite Prevalansı Acıbadem Üniversitesi Sağlık Bilimleri Dergisi 2014;5:141-51.

43. Şimşek F, Ulukol B, Berberoğlu M, ve ark. Ankara'da Bir Illköğretim Okulu ve Lisede Obezite Sıkığı. Ankara Üniversitesi Tıp Fakültesi Mecmuası 2005; 58:163-16.

44. Fatih Önsüz MF, Zengin Z, Özkan M, Şahin H, Sibel Gedikoğlu, Semra Erseven, Hızır Dişli, Hasan Bektaş Sakarya mj.2001;1:86-92.

45. Stunkard A, Sorenson T, Haris C. 1986. An Adaption Study of Human Obesity. N.Engl. J. Med;314:193-8.

46. Mühlig $Y$, Wabitsch M, Moss A, Hebebrand J. Weight loss in children and adolescents. Dtsch Arztebl Int 2014;111:818-24.

47. Zhang Y, Proenca R, Maffei M. Positional cloning of the mouse obese gene and its human homologue. Nature 1994;372:425-32.

48. Clément K. Leptin and the genetics of obesity. Acta Paediatr 1999; Suppl 428:51-7.

49. Hekimoğlu A. Leptin ve Fizyopatolojik Olaylardaki Rolü. Dicle Tıp Dergisi 2006;4:259-67.

50. Ratke J, Entschladen F, Niggemann B. Leptin stimulates the migration of coloncarcinoma cells by multiple signaling pathways. Endocrine-related cancer 2010;17:179-89.

51. Danese A, Dove R, Belsky DW, et all. Leptin deficiency in maltreated children. Transl Psychiatry 2014;4:1-5.
52. Friedman JM. The alphabet of weight control. Nature 1997;385:119-20.

53. Sorensen TIA, Echwald SM, Holm JC: Leptin in obesity. BMJ1996;313:953-4.

54. Milani D, Cerutti M, Pezzani L, Maffei P, Milan G, Esposito S. Syndromic obesity: clinical implications of a correct diagnosis. Ital J Pediatr 2014:2;40:33

55. Marshall JD, Maffei P, Collin GB, Naggert JK: Alström syndrome: genetics and clinical overview. Curr Genomics 2011;12: 225-35.

56. Zhu J, Cao Q, Zhang N, Zhao L. Prader-willi syndrome: A case report and a Chinese literature review. Intractable Rare Dis Res 2013;2:123-6.

57. Cassidy SB, Schwartz S, Miller JL, Driscoll DJ. Prader-Willi syndrome. Genet Med 2012;14:10-26.

58. Butler MG. Prader-Willi syndrome: obesity due to genomic imprinting. Curr Genomics 2011;12:204-15.

59. Goldstone AP, Holland AJ, Hauffa BP, Hokken-Koelega AC, Tauber M; speakers contributors at the Second Expert Meeting of the Comprehensive Care of Patients with PWS.Recommendations for the diagnosis and management of Prader-Willi syndrome. J Clin Endocrinol Metab 2008;93:4183-97.

60. Aycan Z, Baş VN. Prader-Willi syndrome and growth hormone deficiency. J Clin Res Pediatr Endocrinol 2014;6:62-7.

61. Loche S, Carta L, Ibba A, Guzzetti C. Growth hormone treatment in non-growth hormone-deficient children. Ann Pediatr Endocrinol Metab 2014;19:1-7.

62. Cassidy SB, McCandless SE. Prader-Willi syndrome. In: Cassidy SB, Allanson JE (eds). Management of Genetic Syndromes (2nd ed). New Jersey: Wiley-Liss, 2005: 429-48.

63. Uzun H, Ar K, Aktaş A ve ark: A case of Bardet Biedl Sydrome. Düzce Tıp Fakültesi Derg 2008;3:60-3.

64. M'hamdi 0, Ouertani I, Chaabouni-Bouhamed H. Update on the genetics of bardet-biedl syndrome. Mol Syndromol 2014;5:51-6.

65. lannello S, Bosco P, Cavaleri A, Camuto M, Milazzo P, Belfiore F: A review of theliterature of Bardet-Biedl disease and report of three cases associated with metabolic syndrome and diagnosed after the age of fifty. Obes Rev 2002;3:123-35.

66. Bjorntorp P. International Textbook of Obesity Turkce, 1.Baskı, And yayıncılık, İstanbul, 2002.

67. Eckel RH. Obesity: Mechanisms and Clinical Management Lippincott Williams \& Wilkins 2003.

68. Stewart AL, Brook RH. Effects of being overweight. Am J Publ Helth 1983;73:171-8.

69. Whitaker R, Wright J, Pepe M, et al Predicting adult obesity from childhood and parent obesity. N Engl J Med 1997;337:869-73.

70. Pears J, Jung RT, Gunn A. Long-term weight changes in treated hyperthyroid and hypothyroid patients. Scott Med J 1990;35:180-2.

71. Hoogwerf BJ, Nuttall FQ. Long-term weight regulation in treated hyperthyroid and hypothyroid subjects. Am J Med 1984;76:963-70.

72. Brennan BMD, Rahim A, Blum WF, etal. Hyperleptinaemia in young adults followingcranial irradiation in childhood: growth hormone deficiency or leptin insensitivity? Clin Endocrinol 1999;50:163-9. 
73. Sencer E. Endokrinoloji, Metabolizma ve Beslenme Hastalıkları, 1.Baskı, Nobel Tıp kitabevleri, İstanbul, 2001.

74. Ridaura VK, Faith JJ, Rey FE, Cheng J, Duncan AE, Kau AL, Griffin NW, Lombard V, Henrissat B, Bain JR. Gut microbiota from twins discordant for obesity modulate metabolism in mice. Science 2013;341:1241-214.

75. Arslan N. Obesity, fatty liver disease and intestinal microbiota. World J Gastroenterol. 2014;20:16452-63.

76. Yıldırım AE, Altun R. Güncel Gastroenteroloji.18/1 http://guncel.tgv.org.tr/ journal/48/pdf/100169.pdf

77. Lozupone CA, Stombaugh JI, Gordon JI, et al Diversity, stability and resilience of the human gut microbiota. Nature 2012;489:220-30.

78. Suau A, Bonnet R, Sutren M, et al Direct analysis of genes encoding $16 \mathrm{~S}$ rRNA from complex communities reveals many novel molecular species within the human gut. Appl Environ Microbiol 1999;65:4799-807.

79. Ley RE, Peterson DA, Gordon Jl. Ecological and evolutionary forces shaping microbial diversity in the human intestine. Cell. 2006;124:837-48.

80. Angelakis E, Armougom F, Million M, Raoult D. The relationship between gut microbiota and weight gain in humans. Future Microbiol 2012;7:91-109.

81. Sweeney TE, Morton JM. The human gut microbiome: areview of the effect of obesity and surgically induced weight loss. JAMA Surg 2013;148: 563-9.

82. Verdam FJ, Fuentes $\mathrm{S}$, de Jonge $\mathrm{C}$, et al Human intestinal microbiota composition is associated with local and systemic inflammation in obesity. Obesity (Silver Spring) 2013; 21.

83. Bervoets L, Van Hoorenbeeck K, Kortleven I et al Differences in gut microbiota composition between obese and lean children: a cross-sectional study. Gut Pathog 2013;5:10.

84. Xu P, Li M, Zhang J, Zhang T. Correlation of intestinal microbiota with overweight and obesity in Kazakh school children. BMC Microbiol 2012;12: 283.

85. Santacruz A, Marcos A, Wärnberg J et al Interplay between weight loss and gut microbiota composition in overweight adolescents. Obesity (Silver Spring) 2009;17:1906-15

86. Abdallah Ismail N, Ragab SH, Abd Elbaky A et al Alhosary Y, Fekry D. Frequency of Firmicutes and Bacteroidetesin gut microbiota in obese and normal weight Egyptian children and adults. Arch Med Sci 2011;7:501-07.

87. Cani PD, Amar J, Iglesias MA et al Metabolic endotoxemia initiates obesity and insulin resistance. Diabetes 2007;56:1761-72.

88. Delzenne NM, Cani PD. Interaction between obesity and the gut microbiota: relevance in nutrition. Annu Rev Nutr 2011;31:15-31.

89. DiBaise JK, Zhang $\mathrm{H}$, Crowell MD, et al Gut microbiota and its possible relationship with obesity. Mayo Clin Proc 2008;83:460-9.

90. Nadal I, Santacruz A, Marcos A, et al Shifts in clostridia, bacteroides and immunoglobulincoating fecal bacteria associated with weight loss in obese adolescents. Int J Obes (Lond) 2009;33:758-67.

91. Jumpertz R, Le DS, Turnbaugh PJ, et al Energy-balance studies reveal associations between gut microbes, caloric load, and nutrient absorption in humans. Am J Clin Nutr 2011;94:58-65.
92. Mackowiak PA. The normal microbial flora. N Engl J Med 1982;307:83-93.

93. Generation $\mathrm{M}^{2}$. Media in the lives of 8-to 18-year olds. The Kaiser Family Foundation. [Last accessed on 2014 Jan 22]. Available from:http://www. kff.org/entmedia/mh012010pkg.cfm .

94. Kar SS, Dube R, Kar SS. Childhood obesity-an insight into preventive strategies. Avicenna J Med. 2014;4:88-93.

95. Livingstone MBE. Epidemiology of childhood obesity in Europe. Europe $\mathrm{J}$ Pediatrics 2000;159:14-34.

96. Whitaker RC, Dietz WH. Role of the prenatal environment in the development of obesity. J Pediatr 1998;132:768-76.

97. Strauss RS. Effects of the intrauterine environment onchildhood growth. BrMedBull 1997;53:81-95.

98. Maggio AB, Martin XE, Saunders Gasser C, Gal-Duding C, Beghetti M, Farpour-Lambert NJ, Chamay-Weber C. Medical and non-medical complications among children and adolescents with excessive body weight. BMC Pediatr. 2014 Sep 14;14:232.

99. Day, C.P. Non-alcoholic fatty liver disease: A massive problem. Clin. Med 2011;11:176-8.

100. Vajro P, Lenta, S, Socha P et al Diagnosis of Nonalcoholic Fatty Liver Disease in Children and Adolescents:Position Paper of the ESPGHAN Hepatology Committee. J. Pediatr. Gastroenterol. Nutr 2012;54:700-13.

101. Schwimmer, J.B.; Deutsch, R.; Kahen, T.; Lavine, J.E.; Stanley, C.; Behling, $\mathrm{C}$. Prevalence of fatty liver in children and adolescents. Pediatrics 2006;118:1388-93.

102. Saadeh, S, Younossi ZM, Remer EM et al Gramlich, The utility of radiological imaging in nonalcoholic fatty liver disease.Gastroenterology 2002;123: 745-50.

103. Yang $M$, Gong $S$, Ye $S Q$, et al Non-alcoholic fatty liver disease in children: focus on nutritional interventions. Nutrients. 2014 0ct 28;6:4691-705.

104. Fitch A, Fox C, Bauerly K et al . Institutefor Clinical Systems Improvement. Prevention and Management of Obesity for Children and Adolescents.Published July 2013.avaible. https://www.icsi.org/_asset/tn5cd5/ObesityChildhood.pdf.

105. Baltacý G. Obezite tedavisinde egzersizin yeri, 1.Ulusal Adolesan Saðlýoý Kongresi, 28 Kasým-01 Aralýk 2006 Kongre Kitabý, s.131-133, Ankara, 2006.

106. Sothern MS, Udall JN, Suskind, RM et al Weight loss and growth velocity in obese children after very low calorie diet, exercise, and behavior modification. Acta Paediatr 2000;89:1036-43.

107. Atalay A, Kutsal YG. Pediatrik obezite ve egzersiz. Katkı Pediatri Dergisi, 2000;21:537-48.

108. Hillsdon M, Thorogood M, Anstiss T, Morris J. Randomised controlled trials ofphysical activity promotion: a review. Journal of Epidemiology and Community Health 1995;49:448-53.

109. Atkins D, Best D, Briss PA, Eccles M, et all. GRADE Working Group. Grading quality of evidence and strength of recommendations. BMJ. 2004;19;328. 
110. Swiglo BA, Murad MH, Schünemann HJ, Kunz R, Vigersky RA, Guyatt GH, Montori VM. A case for clarity, consistency, and helpfulness: state of the art clinical practice guidelines in endocrinology using the grading of recommendations, assessment, development, and evaluation system. J Clin Endocrinol Metab. 2008 Mar;93:666-73. doi: 10.1210/jc.2007-1907. Epub 2008 Jan 2.

111. Trowbridge FL, Sofka D, Holt K, Barlow SE. Management of child and adolescent obesity: study design and practitioner characteristics. Pediatrics. 2002;110:205-09.

112. Sondike SB, Copperman N, Jacobson MS. Effects of a low-carbohydrate diet on weight loss and cardiovascular risk factor in overweight adolescents. J Pediatr 2003;142:253-8.

113. Köksal G, Gökmen H. Çocuklar hastalıklarında beslenme tedavisi. Hatipoğlu Yayınevi, Ankara 2000.

114. Türkiye Obezite (Şişmanlık) ile Mücadele ve Kontrol Programı (2010-2014) T.C. Sağlık Bakanlığı Temel Sağlık Hizmetleri Genel Müdürlüğü, Ankara 2010.

115. Robinson TN. Reducing children's television viewing to prevent obesity: a randomized controlled trial. JAMA. 1999;282:1561-7.

116. Kelishadi R1, Azizi-Soleiman F. Controlling childhood obesity: A systematic review on strategies and challenges. J Res Med Sci 2014 Oct;19:9931008.

117. http://beslenme.gov.tr/content/files/home/obesity prevention and contro program of Turkey 2010 2014.pdf erişim tarihi Aralık 2014.

118. Barlow SE. Expert committee recommendations regarding the prevention, assessment, and treatment of child and adolescent overweight and obesity: summary report. Pediatrics 2007;120:164-92.

119. Yanovski JA. Intensive therapies for pediatric obesity. Pediatr Clin North Am 2001;48:1041-53.

120. Sherafat-Kazemzadeh R, Yanovski SZ, Yanovski JA. Pharmacotherapy for childhood obesity: present and future prospects. Int J Obes (Lond) 2013;37:1-15.
121. CDER Division of Metabolic and Endocrine Drug Products (HFD-510).Clinical review for NDA 20-766/S018. Rockville, MD: Food and Drug Administration; 2003. Available from: www.fda.gov/downloads/drugs/ developmentapprovalprocess/developmentresources/ucm163350.pdf. Accessed 2011 Jan 18.

122. Maahs D, de Serna DG, Kolotkin RL, Ralston S, Sandate J, Qualls C, et al Randomized, double-blind, placebo-controlled trial of orlistat for weight loss in adolescents. Endocr Pract 2006;12:18-28.

123. McDuffie JR, Calis KA, Uwaifo Gl, Sebring NG, Fallon EM, Frazer TE, et al Efficacy of orlistat as an adjunct to behavioral treatment in overweightAfrican American and Caucasian adolescents with obesity-related co-morbid conditions. J Pediatr Endocrinol Metab 2004;17:307-19.

124. Dunican KC, Desilets AR, Montalbano JK. Pharmacotherapeutic options for overweight adolescents. Ann Pharmacother 2007;41:1445-55. Epub 2007 Jul 24.

125. Freemark M. Pharmacotherapy of childhood obesity: an evidence-based, conceptual approach. Diabetes Care 2007;30:395-402.

126. Srinivasan S, Ambler GR, Baur LA, Garnett SP, Tepsa M, Yap F, et alRandomized, controlled trial of metformin for obesity and insulin resistance in children and adolescents: improvement in body composition and fasting insulin. J Clin Endocrinol Metab 2006;91:2074-80.

127. Ten S, Maclaren N. Insulin resistance syndrome in children. J Clin Endocrinol Metab 2004;89:2526-39.

128. Inge $\mathrm{TH}$, Krebs N, Garcia V, et al Bariatric surgery for severely overweight adolescents: concerns and recommendations. Pediatrics 2004;114:217-23.

129. Wittgrove AC, Buchwald H, Sugerman $H$, et al; American Society for Bariatric Surgery. Surgery for severely obese adolescents: further insight from the American Society for Bariatric Surgery. Pediatrics 2004;114:253-4. 